\title{
Divergência genética entre cultivares comerciais de milho em baixas altitudes no Tocantins, safra $2007 / 2008^{1}$
}

\author{
Genetic divergence among the commercials corns cultivars in low heigts in Tocantins \\ harvest 2007/2008
}

\author{
Michel Antônio Dotto ${ }^{2 *}$, Flávio Sérgio Afférri ${ }^{3}$, Joênes Mucci Peluzio ${ }^{4}$, Aurélio Vaz de Melo ${ }^{3}$ e Edmar Vinícius de \\ Carvalho ${ }^{5}$
}

\begin{abstract}
Resumo - O Estado do Tocantins apresenta boas condições edafoclimáticas para o desenvolvimento da cultura do milho, porém possui baixa média de produtividade, sendo esta atribuída principalmente a falta de genótipos específicos a este ambiente e manejo incorreto da cultura. Neste contexto, foi avaliada a divergência genética entre cultivares comerciais de milho sob diferentes condições edafoclimáticas no Tocantins. Os experimentos foram realizados em três ambientes, sendo um em Gurupi-TO e dois em Palmas-TO, ambas as áreas experimentais pertencentes à Universidade Federal do Tocantins. O delineamento experimental foi aleatorizado em blocos, com quatro repetições, utilizando 24 híbridos comerciais de milho. A divergência genética foi avaliada por meio de métodos de análise multivariada, sendo as cultivares agrupadas com base na distância generalizada de Mahalanobis e, posteriormente, utilizado o método de otimização de Tocher. As cultivares apresentaram divergência genética no ambiente de Palmas-TO plantio do cedo, sendo as contribuições das características influenciadas pela interação genótipo $\times$ ambiente. Dentre as cultivares, as de polinização aberta DSSCAMPEÃO e BR106 foram as mais divergentes. Dentre os híbridos simples, DAS2B710 e XGN6370 foram os mais divergentes.
\end{abstract}

Palavras-chave - Milho. Melhoramento genético. Genética vegetal.

\begin{abstract}
The Tocantins State has good soil and climatic conditions for the development of corn, but has low average productivity, which is mostly attributed to lack of specific genotypes in this environment and incorrect crop management. In this context were evaluated genetic diversity among corn cultivars under different climate conditions in Tocantins. The experiments were conducted in three locations, one in Gurupi-TO and two in Palmas-TO, both experimental areas belonging to the Universidade Federal of Tocantins. The experimental design was randomized blocks with four replications using 24 commercial corn cultivars. Genetic divergence was evaluated by multivariate analysis methods, and cultivars clustered based on the Mahalanobis generalized distance, and then used the Tocher optimization method. The cultivars showed genetic divergence in environment of Palmas-TO early planting, and the characteristics contributions influenced by genotype $\times$ environment interaction. Among the cultivars, the open pollination DSSCAMPEÃO and BR106 were the most divergent. Among the simple hybrids, DAS2B710 and XGN6370 were the most divergent.
\end{abstract}

Key words - Corn. Enhancement-genetic. Plant genetics.

\footnotetext{
* Autor para correspondência

${ }^{1}$ Recebido para publicação em 10/11/2009; aprovado em 07/11/2010

Pesquisa desenvolvida junto a Universidade Federal do Tocantins, Campus Universitário de Gurupi

2Programa de Pós-Graduação em produção vegetal, UFT, Campus Universitário de Gurupi, Caixa Postal 66, Gurupi-TO, Brasil, 77.402-970, micheldotto@hotmail.com

${ }^{3}$ Universidade Federal do Tocantins, Campus Universitário de Gurupi, Caixa Postal 66, Gurupi-TO, Brasil, 77.402-970, flavio@mail.uft.edu.br, vazdemelo@mail.uft.edu.br

${ }^{4}$ Universidade Federal do Tocantins, Campus Universitário de Palmas, Caixa Postal 66, Palmas-TO, Brasil, 77.410-000, joenesp@mail.uft.edu.br

${ }^{5}$ Programa de Pós-Graduação em produção vegetal, UFT, Campus Universitário de Gurupi, Caixa Postal 66, Gurupi-TO, Brasil, 77.402-970,

ed.vinicius_carvalho@hotmail.com
} 


\section{Introdução}

A safra de milho no Brasil em 2008/2009 foi de 51.232.447 milhões de toneladas, configurando redução de 11,5\% sobre o período anterior. Esse decréscimo se deve, principalmente, a redução da área plantada, que ficou em torno de $4,0 \%$, e ainda menor média de produtividade devido às variações das condições climáticas que afetaram negativamente a cultura (IBGE, 2009).

A média nacional de produtividade de milho é de 3.715 quilos por hectare, que ainda é baixa comparando-se com regiões brasileiras que conseguem atingir excelentes produtividades, acima de 6.000 quilos por hectare.

Os melhoristas vêm usando a avaliação de divergência genética na seleção de parentais que apresentam altos valores nas características desejadas e com genótipos mais divergentes (RINALDI et al., 2007). O princípio do estudo de divergência genética é o de selecionar os genótipos mais produtivos e que sejam divergentes entre eles, auxiliando na seleção de genitores em futuras sínteses de híbridos e/ou populações de extração de linhagens (PASSOS et al., 2007).

A classificação das linhagens em grupos heteróticos permite visualizar, com antecedência, quais as melhores combinações híbridas, podendo evitar cruzamentos desnecessários dentro de um grupo homogêneo, priorizando, assim, cruzamentos entre os grupos mais contrastantes. Com isso, além de diminuir consideravelmente o número de cruzamentos a serem realizados, aumenta as possibilidades de obtenção de combinações híbridas com maior heterose (MORO et al., 2007).

De acordo com Melo et al. (2001), existem vários trabalhos na literatura que relatam que quanto maior a divergência genética entre os parentais maior será a heterose e, conseqüentemente, maior a produtividade do híbrido.

A identificação da influência de cada característica na divergência genética entre cultivares é importante no direcionamento dos programas de melhoramento na obtenção de cultivares mais produtivas. A divergência genética tem sido estudada em várias culturas com base nas características agronômicas, visando à seleção de genitores para formação de híbridos ou mesmo para a formação de novas populações segregantes oriundas do cruzamento dos genótipos de maior divergência (AMORIM et al., 2007; ARRIEL et al., 2007; BARBIERI et al., 2005; BONETT et al., 2006; MACHADO et al., 2002 e VIANA et al., 2006).
Smith et al. (1999) sugerem que quando o número de germoplasma é grande e sem estabelecimento de grupos heteróticos é importante, primeiramente, identificar grupos geneticamente similares no germoplasma. O segundo passo é sintetizar e avaliar os cruzamentos em dialelos ou cruzamentos fatoriais entre os genótipos representativos de cada grupo ou entre compostos produzidos dos genótipos de cada grupo. Finalmente, o terceiro passo seria a seleção de grupos promissores com base no desempenho do híbrido.

A ausência de informação tem dificultado a formação de grupos heteróticos adequados na utilização em programas de melhoramento, visando à obtenção das melhores combinações híbridas e/ou proporcionando maior variabilidade nas futuras populações de extração de linhagens. Com isso, objetivou-se com este trabalho avaliar a divergência genética entre 24 cultivares comerciais de milho sob diferentes condições edafoclimáticas no Tocantins, na safra 2007/2008.

\section{Material e métodos}

Os experimentos foram instalados nos Campos Experimentais da Universidade Federal do Tocantins - UFT, situados nas cidades de Palmas - TO, a $10^{\circ} 10^{\prime}$ de latitude sul, $48^{\circ} 21^{\prime}$ ' de latitude Oeste e altitude de 212 metros, e em Gurupi - TO, a $11^{\circ} 43^{\prime}$ de latitude Sul, $49^{\circ} 15^{\prime}$ de longitude Oeste e altitude de 287 metros, ambos em solo do tipo Latossolo Vermelho-Amarelo, textura arenosa distrófico.

Os delineamentos utilizados foram aleatorizados em blocos, com quatro repetições, utilizando 24 cultivares comerciais (TAB. 1), semeados na safra de 2007/2008, em duas linhas com quatro metros de comprimento por parcela, com espaçamento de um metro entre linhas e 0,20 metros entre plantas.

Os dados climatológicos de temperatura e precipitação foram obtidos através das estações automáticas do Instituto Nacional de Meteorologia (INMET), localizadas nos campus universitários da Universidade Federal do Tocantins, nas cidades de Gurupi e Palmas, no Estado do Tocantins. A proximidade das estações climatológicas em relação à área em que estavam instalados os experimentos sugere boa precisão dos dados nos ambientes estudados.

As semeaduras foram realizadas nos dias 19/12/2007, na primeira época em Palmas (PalmasTO plantio do cedo), e em 23/01/2008, na segunda época (Palmas-TO plantio do tarde). Já em Gurupi, o plantio foi realizado em $06 / 12 / 2007$, totalizando três ambientes distintos. 
Tabela 1 - Descrição das Cultivares de milho avaliadas quanto ao tipo de cultivar, ciclo e empresa produtora

\begin{tabular}{|c|c|c|c|c|}
\hline $\mathrm{N}^{\mathrm{o}}$ & Cultivar & Tipo de Cultivar & Ciclo & Empresa Produtora \\
\hline 1 & XGN5320 & Híbrido Simples & Precoce & Agromen \\
\hline 2 & XGN7320 & Híbrido Simples & Super-precoce & Agromen \\
\hline 3 & XGN6311 & Híbrido Simples & Precoce & Agromen \\
\hline 4 & XGN7289 & Híbrido Triplo & Precoce & Agromen \\
\hline 5 & AGN30A06 & Híbrido Simples & Super-precoce & Agromen \\
\hline 6 & XGN4210 & Híbrido Triplo & Precoce & Agromen \\
\hline 7 & XGN6370 & Híbrido Simples & Semi-precoce & Agromen \\
\hline 8 & XGN6318 & Híbrido Simples & Semi-precoce & Agromen \\
\hline 9 & AGN20A06 & Híbrido Simples & Super-precoce & Agromen \\
\hline 10 & CD356 & Híbrido Duplo & Precoce & Cooddetec \\
\hline 11 & CD319 & Híbrido Triplo & Precoce & Cooddetec \\
\hline 12 & CD384 & Híbrido Triplo & Precoce & Cooddetec \\
\hline 13 & CD327 & Híbrido Simples Modificado & Precoce & Cooddetec \\
\hline 14 & CD397 & Híbrido Triplo & Precoce & Cooddetec \\
\hline 15 & CD308 & Híbrido Duplo & Precoce & Cooddetec \\
\hline 16 & CD351 & Híbrido Simples & Precoce & Cooddetec \\
\hline 17 & BR106 & Variedade & Precoce & DiSolo \\
\hline 18 & AL. BANDEIRANTE & Variedade & Precoce & DiSolo \\
\hline 19 & DSSCAMPEÃO & Variedade & Precoce & DiSolo \\
\hline 20 & DSS1001 & Híbrido Duplo & Precoce & DiSolo \\
\hline 21 & DAS9364 & Híbrido Simples Modificado & Precoce & Dow Agosciences \\
\hline 22 & DAS2B707 & Híbrido Simples & Precoce & Dow Agosciences \\
\hline 23 & DAS2B587 & Híbrido Simples & Precoce & Dow Agosciences \\
\hline 24 & DAS2B710 & Híbrido Simples & Precoce & Dow Agosciences \\
\hline
\end{tabular}

Foi realizado, em cada ambiente, o preparo do solo no sistema convencional, constando de uma aração e duas gradagens, com o intuito de descompactar a camada superficial e incorporar os restos culturais presentes no perfil superficial do solo.

As principais características químicas do solo em Gurupi foram: $\mathrm{pH}$ em $\mathrm{Cacl}_{2}=5,5 ; \mathrm{P}=1,2 \mathrm{mg} \mathrm{dm}{ }^{-3}$; $\mathrm{K}=80 \mathrm{mg} \mathrm{dm}^{-3} ; \mathrm{Ca}^{2+}=2,2 \mathrm{cmol}_{\mathrm{c}} \mathrm{dm}^{-3} ; \mathrm{Mg}^{2+}=1,0 \mathrm{cmol}_{\mathrm{c}}$ $\mathrm{dm}^{-3} ; \mathrm{H}+\mathrm{Al}=1,8 \mathrm{cmol}_{\mathrm{c}} \mathrm{dm}^{-3} ; \mathrm{MO}=3,2 \%$. Já do solo em que foram conduzidos os experimentos de Palmas as suas principais características foram: $\mathrm{pH}$ em $\mathrm{Cacl}_{2}=$ 6,$0 ; \mathrm{P}=8,4 \mathrm{mg} \mathrm{dm}^{-3} ; \mathrm{K}=60 \mathrm{mg} \mathrm{dm}{ }^{-3} ; \mathrm{Ca}^{2+}=2,3 \mathrm{cmol}_{\mathrm{c}}$ $\mathrm{dm}^{-3} ; \mathrm{Mg}^{2+}=1,2 \mathrm{cmol}_{\mathrm{c}} \mathrm{dm}^{-3} ; \mathrm{H}+\mathrm{Al}=1,5 \mathrm{cmol}_{\mathrm{c}} \mathrm{dm}^{-3} ; \mathrm{MO}$ $=0,7 \%$. A correção da acidez do solo e dos nutrientes foi realizada de acordo com o resultado da análise de solo e as recomendações técnicas da cultura do milho descritas na $5^{\text {a }}$ aproximação de adubação do Estado de Minas Gerais (ALVES et al., 1999).
As semeaduras foram realizadas visando à obtenção de população de 50.000 plantas por hectare. Os controles de pragas e plantas daninhas foram realizados à medida que se fizeram necessários. Aos 30 dias, após as semeaduras, realizaram-se adubações de cobertura seguindo as recomendações da cultura do milho (100 kg ha-1 de N). As colheitas dos experimentos foram realizadas nos dias 11/04/2008, na primeira época de Palmas, dia 03/05/2008, na segunda época de Palmas, e no dia 19/04/2008, em Gurupi - TO.

$\mathrm{Na}$ área útil da parcela, foram avaliadas algumas características agronômicas utilizadas nas análises de divergência genética entre cultivares, sendo: comprimento de espiga em milímetro (CE), altura de plantas em centímetro (AP), altura de espiga em centímetros (AE), diâmetro de espiga em milímetros (DE), produtividade de espigas em $\mathrm{kg} \mathrm{ha}^{-1}$ (PE), produtividade de grãos em $\mathrm{kg} \mathrm{ha}^{-1}$ (PROD) e cor de 
grãos (CG), a coloração dos grãos, seguindo escala estabelecida a priori, variando de 1 a 5 , em que 1 correspondia à cor creme dos grãos; 2 amarelo-claro; 3 amarelo; 4 amarelo-escuro e 5 alaranjado.

Uma estação meteorológica de superfície automáticaé composta de uma unidade de memória central (“data logger") ligada a vários sensores dos parâmetros meteorológicos (pressão atmosférica, temperatura e umidade relativa do ar, precipitação, radiação solar, direção e velocidade do vento, etc), que integra os valores observados minuto a minuto e dos automaticamente a cada hora.

Realizou-se a análise da divergência genética empregando-se métodos multivariados. $\mathrm{Na}$ aplicação da técnica de agrupamento das cultivares, adotou-se a distância generalizada de Mahalanobis como medida de dissimilaridade, que leva em conta o grau de correlação entre os caracteres considerados (CRUZ, 2001). Com relação ao estabelecimento de grupos similares, foi aplicado o método de otimização proposto por Tocher (RAO, 1952). Na realização das análises de variância e divergência genética, utilizado o programa Genes (CRUZ, 2001).

\section{Resultados e discussão}

No ambiente de Gurupi não houve significância pelo teste $\mathrm{F}$ para as cultivares, em todas as características analisadas. Para o plantio realizado em Palmas (plantio do tarde), houve efeito significativo $(\mathrm{p}<0,05)$ na altura de plantas e espigas, para produtividade de espiga e grãos foi significativo $(\mathrm{p}<0,01)$. Nas demais características não houve efeito significativo entre as cultivares $(p>0,05)$.

A primeira época de plantio em Palmas (PalmasTO plantio do cedo) foi o ambiente que proporcionou a maior média de produtividade de grãos $\left(5.715 \mathrm{~kg} \mathrm{ha}^{-1}\right)$, além de apresentar diferenças significativas em todas as características estudadas. Nesta época, o comprimento de espiga (CE), diâmetro de espiga (DE), cor de grão (CG) e produtividade (PROD) obtiveram diferenças significativas $(\mathrm{p}<0,01)$, indicando que houve variabilidade entre as cultivares. Diante das características avaliadas o DE obteve o menor coeficiente de variação (CV) que foi de $4,8 \%$. Já o maior $\mathrm{CV}$ foi observado na característica de $\mathrm{PE}$, que atingiu $14,7 \%$, e nas características CE e AE observaram-se CV de 7,9 e 9,0\%, respectivamente, ficando em posição intermediária. Os coeficientes de variação obtidos indicam boa precisão desses ensaios, de acordo com a classificação de Scapin et al. (1995). As características agronômicas de CE e DE obtiveram as médias de $140,7 \mathrm{~mm}$ e $46,3 \mathrm{~mm}$, respectivamente (TAB. 2).
$\mathrm{Na}$ análise conjunta da Tabela 2, nota-se significância pelo teste $\mathrm{F}$ para fonte de variação "cultivares (C)" para praticamente todas as características, exceto altura de plantas (AP), ressaltando-se: altura de espiga (AE), comprimento de espiga (CE), diâmetro de espiga (DE) e produção de espiga (PE) a significância do teste $\mathrm{F}$ foi relevante $(\mathrm{p}<0,01)$ e para produção de grãos $(\mathrm{PG})$, mostrando-se agronomicamente aceitável ao nível de significância $(\mathrm{p}<0,05)$. Na mesma análise conjunta, para a fonte de variações "ambientes (A)", a significância do teste $\mathrm{F}$ difere-se apenas onde há significância relevante $(\mathrm{p}<0,01)$, nas características de $\mathrm{CE}, \mathrm{DE}$ e $\mathrm{PG}$ não há significância para o teste $\mathrm{F}(\mathrm{p}>0,05)$, indicando que, para ambientes, os contrastes ocorreram definitivamente para algumas características (AP, AE e PE; p < 0,01) (TAB. 2).

As características relativas à produtividade são de grande relevância, onde ficou caracterizada a importância do estudo de cultivares em diferentes ambientes devido à interação entre tais fatores.

A interação cultivares $\times$ ambiente $(\mathrm{C} \times \mathrm{A})$ apresenta que há uma significância pelo teste $\mathrm{F}$ apenas nas características da produtividade (PE e PG), com significância de $\mathrm{p}<0,01$ e $\mathrm{p}<0,05$, respectivamente (TAB. 2).

$\mathrm{Na}$ análise de agrupamento pelo método de Tocher, utilizando as médias das cultivares nos três ambientes (análise conjunta), sendo as cultivares agrupadas em oito grupos, onde o grupo I foi formado por nove cultivares, seguido do grupo III que apresentou cinco cultivares, grupo II com três cultivares, grupos IV e V com dois cultivares cada e grupos VI, VII e VIII com um cultivar cada (TAB. 3 ).

Pode-se observar elevada divergência entre os híbridos comerciais avaliados, explicando a formação dos 8 grupos. A grande divergência genética encontrada entre as cultivares é principalmente devida a sua origem e a composição genética entre elas (cultivares de polinização aberta, híbridos simples, duplos e triplos). As cultivares são heterogêneas entre os grupos e homogêneas dentro do grupo (CRUZ et al., 2004).

Em relação ao cruzamento entre duas cultivares, a capacidade especifica de combinação e seu vigor híbrido (heterose) depende, principalmente, da capacidade de dominância do caráter e da divergência genética entre ambas (FALCONER, 1981). Além, preferencialmente, que sejam adaptadas às condições edafoclimáticas onde serão sintetizadas e avaliadas (ABREU, 1997; DIAS; KAGEYAMA, 1997 e SILVA, 1996). Com isso, há maior possibilidade de sucesso nos cruzamentos, proporcionando maior heterose, através dos indicadores utilizados no presente trabalho. 
Tabela 2 - Resumo da análise de variância, em delineamento aleatorizado em blocos, de características avaliadas em 24 cultivares comerciais de milho em experimentos conduzidos nas cidades de Gurupi e Palmas-TO na safra 2007/08

\begin{tabular}{|c|c|c|c|c|c|c|c|c|}
\hline \multirow{2}{*}{ ENSAIOS } & \multirow{2}{*}{ Fatores de variação } & \multirow{2}{*}{ GL } & \multicolumn{6}{|c|}{ Quadrado Médio } \\
\hline & & & AP & $\mathrm{AE}$ & $\mathrm{CE}$ & $\mathrm{DE}$ & $\mathrm{PE}$ & PG \\
\hline \multirow{5}{*}{ Gurupi-TO } & $\mathrm{BLOCO}$ & 2 & 736,7 & 467,2 & 106,2 & 22,9 & 4008905 & 2575920 \\
\hline & CULTIVARES & 23 & $945,3^{\mathrm{ns}}$ & $289,1^{\mathrm{ns}}$ & $569,7^{\mathrm{ns}}$ & $46,1^{\mathrm{ns}}$ & $5466857^{\mathrm{ns}}$ & $1736223^{\mathrm{ns}}$ \\
\hline & RESÍDUO & 46 & 989,7 & 243,8 & 543,7 & 33,1 & 3514731 & 1215549 \\
\hline & Média & & 228,6 & 94,2 & 149,2 & 45,0 & 9734 & 5403 \\
\hline & $\mathrm{CV}(\%)$ & & 13,76 & 16,5 & 15,6 & 12,8 & 19 & 20 \\
\hline \multirow{5}{*}{$\begin{array}{c}\text { Palmas-TO } \\
\text { Plantio } \\
\text { Cedo }\end{array}$} & BLOCO & 2 & 805,8 & 509,5 & 45,3 & 8,9 & 6226872 & 1030784 \\
\hline & CULTIVARES & 23 & $476,5 * *$ & $406,7 * *$ & $331,1 * *$ & $13,2 * *$ & $10209171 * *$ & $3064880 * *$ \\
\hline & RESÍDUO & 46 & 164,1 & 101,0 & 124,7 & 5,0 & 3119957 & 661466 \\
\hline & Média & & 221,4 & 111,7 & 140,7 & 46,3 & 11993 & 5715 \\
\hline & $\mathrm{CV}(\%)$ & & 5,8 & 9,0 & 7,9 & 4,8 & 14 & 14 \\
\hline \multirow{5}{*}{$\begin{array}{c}\text { Palmas-TO } \\
\text { Plantio } \\
\text { Tarde }\end{array}$} & $\mathrm{BLOCO}$ & 2 & 507,0 & 78,8 & 5176,3 & 84,4 & 39069838 & 12861038 \\
\hline & CULTIVARES & 23 & $219,1 *$ & $250,1 *$ & $300,7^{\mathrm{ns}}$ & $13,9^{\mathrm{ns}}$ & $4483909 * *$ & $2467484 * *$ \\
\hline & RESÍDUO & 46 & 121,2 & 127,1 & 293,1 & 13,3 & 1481771 & 581227 \\
\hline & Média & & 193,0 & 92,5 & 144,9 & 47,1 & 8097 & 5112 \\
\hline & $\mathrm{CV}(\%)$ & & 5,7 & 12,2 & 11,8 & 7,7 & 15 & 14 \\
\hline \multirow{7}{*}{$\begin{array}{l}\text { Análise } \\
\text { conjunta }\end{array}$} & $\mathrm{BLOCO} / \mathrm{AMB}$ & 6 & 683,2 & 351,9 & 1776,0 & 38,7 & 16435205 & 5489247 \\
\hline & CULTIVARES (C) & 23 & $653,2^{\mathrm{ns}}$ & $578,1 * *$ & $602,0 * *$ & $33,5 * *$ & $11765517 * *$ & $4852186^{*}$ \\
\hline & AMBIENTES (A) & 2 & $25584,7 * *$ & $8108,0 * *$ & $1297,0^{\mathrm{ns}}$ & $79,6^{\mathrm{ns}}$ & $275535737 * *$ & $6550134^{\mathrm{ns}}$ \\
\hline & $\mathrm{C} \times \mathrm{A}$ & 46 & $493,9 \mathrm{~ns}$ & $184,0^{\mathrm{ns}}$ & $299,7^{\mathrm{ns}}$ & $19,8^{\mathrm{ns}}$ & $4197209 * *$ & $1208200 *$ \\
\hline & RESÍDUO & 138 & 425,0 & 157,4 & 320,5 & 17,1 & 2705486 & 819414 \\
\hline & Média & & 214,3 & 99,5 & 145,0 & 46,1 & 9942 & 5410 \\
\hline & $\mathrm{CV}(\%)$ & & 9,6 & 12,6 & 12,4 & 9,0 & 16 & 16 \\
\hline
\end{tabular}

**, * significativo pelo teste de F a 1 e 5\%, respectivamente; ${ }^{\text {ns }}$ - não significativo pelo teste de F a 5\%. AP: Altura de plantas (cm); AE: Altura de espigas (cm); CE: comprimento de espigas (mm); DE: Diâmetro de espigas (mm); PE: Produtividade de espigas (kg ha $\left.{ }^{-1}\right)$, PG: Produtividade de Grãos $\left(\mathrm{kg} \mathrm{ha}^{-1}\right)$ e GL: Graus de liberdade

Tabela 3 - Agrupamento de cultivares de milho, pelo método de Tocher, com base na distância generalizada de Mahalanobis, considerando a altura de plantas e espigas, comprimento e diâmetro de espigas, produtividade de espigas e grãos em ensaios realizados em Gurupi e Palmas - TO, na safra de 2007/08

\begin{tabular}{cc}
\hline Grupo & Cultivares \\
\hline I & DSSCAMPEÃO, DAS2B710, XGN7320, AGN20A06, XGN7289, CD327, CD351, CD319, CD356 \\
II & XGN6318, CD384, CD308 \\
III & DAS9364, DAS2B707, AGN30A06, DSS1001, AL BANDEIRANTE \\
IV & CD397, DAS2B587 \\
V & XGN5320, XGN6311 \\
VI & XGN6370 \\
VII & XGN4210 \\
VIII & BR106 \\
\hline
\end{tabular}


A informação da divergência genética entre cultivares pode nos direcionar quanto ao nível de variabilidade que se deseja alcançar dentro dos cruzamentos realizados entre as cultivares. Visto que, na análise de variância (conjunta - média dos três ambientes), o cruzamento entre as cultivares DSSCAMPEÃO (Grupo I) com o BR106 (Grupo VIII) proporcionará maior variabilidade nas futuras populações segregantes, considerando-se que os dois materiais são cultivares de polinização aberta. Levando em consideração o interesse de maior fixação de genes favoráveis a altas produtividades, sem se preocupar com a menor base genética, o cruzamento entre os híbridos simples DAS2B710 (Grupo I) com o XGN6370 (Grupo VI) pode proporcionar a síntese de um híbrido duplo ou a perspectiva de obtenção de híbridos crípticos. Por outro lado, pode-se obter maior variabilidade e fixação de genes favoráveis à produtividade ao cruzar os híbridos triplos XGN7289 (Grupo I) com o XGN4210 (Grupo VI), sendo envolvido nestes três linhagens de cada híbrido.

$\mathrm{Na}$ identificação dos parentais mais divergentes, sugere-se que sejam selecionados, dentro dos grupos, os parentais com maiores médias em relação às características que se deseja melhorar, objetivando, desse modo, a máxima concentração de alelos favoráveis, conforme os objetivos da seleção (CRUZ et al., 2004). Desse modo, Dharmalingam e Kadambavanasundaram(1989) afirmaram que a seleção de parentais dos grupos mais divergentes pode ser feita com base nas médias dos caracteres que tenham maior influência na produção em nível de campo.

Levando em consideração a grande mão-de-obra no desenvolvimento de programas de melhoramento de milho, específicos para micro-regiões, é difícil, visto que os primeiros cruzamentos têm que ser amplos. Com isso, a melhor estratégia seria a utilização das informações da análise conjunta dos três ambientes. Podendo, no futuro, realizar apenas as avaliações e seleção das cultivares comerciais nas condições específicas.
$\mathrm{Na}$ análise individual dos ambientes, houve diferença na contribuição relativa das características quanto à divergência genética, visto que a contribuição da altura de plantas foi maior no plantio do tarde em Palmas $(16,5 \%)$ e o menor em Gurupi $(6,8 \%)$. O mesmo ocorreu na produtividade de grãos (33,2 e 12,4\% em Palmas plantio do tarde e Gurupi, respectivamente). Isso demonstra que as condições edafoclimáticas têm influência direta no comportamento dos híbridos com relação às características estudadas (TAB. 4), porém, quando se observa apenas a produtividade de grãos, as diferenças entre as médias contrastantes foram de apenas $10,5 \%$ entre os ambientes, provavelmente, em função da similaridade entre os ambientes (FIG. 1 e 2).

Quanto à análise de contribuição relativa das características na formação dos grupos divergentes, levando em consideração a análise conjunta dos três ambientes, o DE $(76,3 \%)$ foi a característica que mais contribuiu na divergência genética entre os genótipos, sendo a produtividade de grãos a que menos contribuiu, apenas com $0,02 \%$ na divergência genética entre as cultivares. Éimportante conhecera influência das principais características na divergência genética das linhagens, pois estas irão direcionar os trabalhos de melhoramento genético e potencializar as chances de sucesso nas sínteses de híbridos. Alom et al. (2003) observaram, nos genótipos de milho, que a altura de plantas foi uma das características que mais contribuiu na divergência genética.

A contribuição relativa (\%), presente na Tabela 4, quando se observa a análise conjunta, as características com menor contribuição (produtividade de grãos e produtividade de espiga) foram justamente às únicas características com significância pelo teste $\mathrm{F}$, na interação cultivares $\times$ ambiente. Portanto, a oscilação da classificação das cultivares ao longo dos ambientes indiretamente descredenciam características diretamente relacionadas à produtividade, nesse caso produtividade de espiga e produtividade de grãos, como principais na

Tabela 4 - Contribuição relativa de divergência genética (em \%) na análise de variância das características avaliadas de híbridos comerciais de milho em ensaios conduzidos nas cidades de Gurupi e Palmas (duas épocas), na safra 2007/08

\begin{tabular}{lcccc}
\hline \multicolumn{1}{c}{ Características } & Gurupi - TO & Palmas-TO - Plantio Cedo & Palmas-TO - Plantio Tarde & ACTA \\
\hline Altura de plantas & 6,8 & 11,7 & 16,5 & 11,8 \\
Altura de espigas & 19,4 & 14,1 & 19,2 & 0,56 \\
Comprimento de espigas & 10,9 & 19,7 & 9,6 & 11,3 \\
Diâmetro de espigas & 20,5 & 12,7 & 7,9 & 76,3 \\
Produtividade de espigas & 29,8 & 7,5 & 13,4 & 0,03 \\
Produtividade de grãos & 12,4 & 34,0 & 33,2 & 0,02 \\
\hline
\end{tabular}

ACTA - Análise conjunta de todos os ambientes 
análise de divergência em um conjunto de ambientes. Por outro lado, quando se procura divergência entre cultivares para ambientes específicos, a produtividade pode ser uma característica importante na identificação de divergência genética entre cultivares (Palmas - TO, plantio do cedo $34,0 \%$, e Palmas - TO, plantio do tarde $33,2 \%$ ).

Mesmo as características tendo influenciado diferentemente a divergência ocorrida entre as cultivares, pode-se dizer que todas têm importância relevante no melhoramento do milho, quando se considera a cadeia produtiva no todo e a utilização comercial que a cultivar será explorada. As condições climáticas nos três ambientes apresentaram variações que podem influenciar diferentemente os estádios fenológicos da cultura (FIG. 1 a 2).

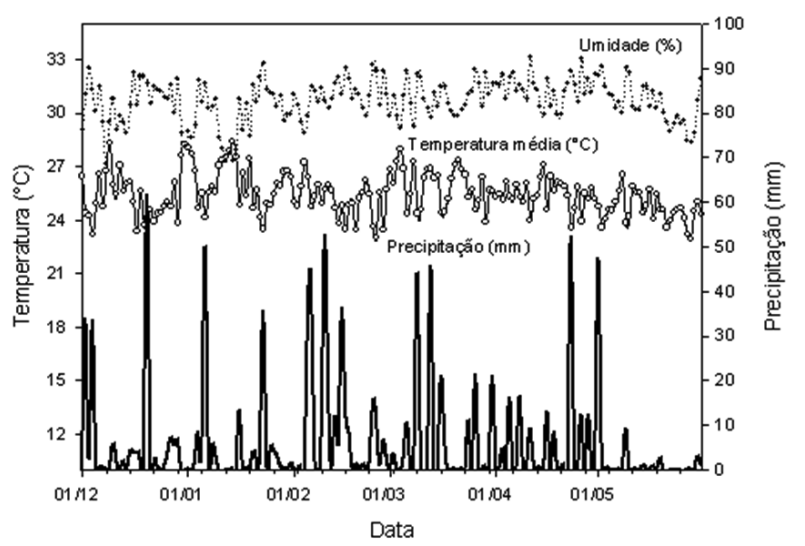

Figura 1 - Variação diária da umidade, temperatura média do ar e precipitação pluvial de novembro de 2007 a maio de 2008, UFT, Palmas - TO

Fonte: INMET, 2008. (Estação Climatológica de Palmas - TO)

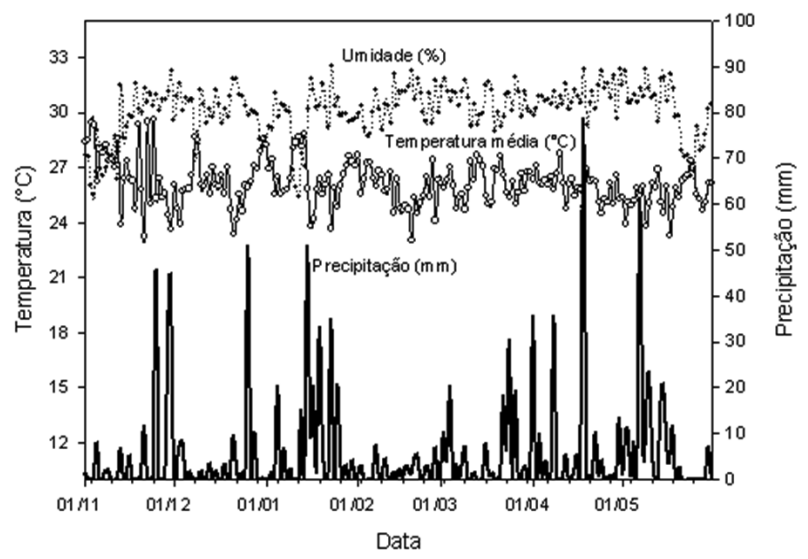

Figura 2 - Variação diária da umidade, temperatura média do ar e precipitação pluvial de novembro de 2007 a maio de 2008, UFT, Gurupi - TO

Fonte: INMET, 2008.(Estação Climatológica de Gurupi - TO)
Outro fator predominante entre as diferenças de ambiente, principalmente, o de Palmas-TO plantio do cedo e em Gurupi, é a maior freqüência de chuvas no período do experimento. Além das diferenças entre altitudes que influenciam a produtividade (FIG. 1 e 2).

\section{Conclusões}

1. As contribuições das características estudadas são influenciadas pela interação genótipo $\times$ ambiente;

2. Existe divergência genética entre as cultivares testadas;

3. Dentre as cultivares, as de polinização aberta DSSCAMPEÃO e o BR106 são os mais divergentes;

4. Dentre os híbridos simples o DAS2B710 e o XGN6370 são os mais divergentes.

\section{Agradecimentos}

Ao Conselho Nacional de Desenvolvimento Científico e Tecnológico (CNPq), pelo apoio financeiro.

A Coordenação de Aperfeiçoamento de Pessoal de Nivel Superior (CAPES), pela concessão da bolsa no Programa Nacional de Pós -Doutorado (PNPD).

\section{Referências}

ABREU, A. F. B. Predição do potencial genético de populações segregantes do feijoeiro utilizando genitores inter-raciais. 1997. 79 f. Tese (Doutorado em Genética e Melhoramento de Plantas) - Universidade Federal de Lavras, Lavras.

ALOM, A. K. M. M. et al. Genetic Divergence in Maize (Zea mays L.). Pakistan Journal of Biological Sciences, V. 6, N. 22, p. 1910-1911, 2003.

ALVES, V. M. C. et al. Interpretação dos resultados das análises de solos. In: RIBEIRO, A. C.; GUIMARÃES, P. T. G.; ALVAREZ V., V. H. (Ed.). Recomendação para o uso de corretivos e fertilizantes em Minas Gerais: 5a Aproximação. Viçosa: Comissão de Fertilidade do Solo do Estado de Minas Gerais, 1999. p. 314-322.

AMORIM,E.P.et al. Divergência genética em genótipos de girassol. Ciência Agrotecnologia, v. 31, n. 06, p. 1637-1644, 2007.

ARRIEL, N. H. C. et al. Genetic divergence in sesame based on morphological and agronomic traits. Crop Breeding and Applied Biotechnology, v. 07, p. 253-261, 2007.

BARBIERI, R. L. et al. Divergência genética entre populações de cebola com base em marcadores morfológicos. Ciência Rural, v. 35, n. 02, p. 303-308, 2005. 
BONETT, L. P. et al. Divergência genética em germoplasma de feijoeiro comum coletado no estado do Paraná, Brasil. Semina: Ciências Agrárias, v. 27, n. 4, p. 547-560, 2006.

CRUZ, C. D. Programa GENES: aplicativo computacional em genética e estatística versão Windows. Viçosa - MG. UFV, 2001. 442 p.

CRUZ, C. D.; REGAZZI, A. J.; CARNEIRO, P. C. S. Modelos biométricos aplicados ao melhoramento genético. 3. ed. Viçosa, MG. UFV, 2004. 480 p.

DHARMALINGAM, V.; KADAMBAVANASUNDARAM, $\mathrm{M}$. Genetic divergence in cowpea [Vigna unguiculata (L.) Walp.]. Madras Agricultural Journal, Coimbatore, v. 76, n. 07, p. 394-399, 1989.

DIAS, L. A. S.; KAGEYAMA, P.Y. Multivariate genetic divergence and hybrid performance of cacao (Theobromacacao L.). Revista Brasileira de Genética, v. 20, n. 01, p. 63-70, 1997.

FALCONER, D. S. Introduction to quantitative genetics. 2.ed. London: Longman, 1981. 340 p.

INSTITUTO NACIONAL DE METEOROLOGIA (INMET). Monitoramento das Estações Automáticas, Gurupi e Palmas - TO, Dados. 2007/2008. Disponível em: $<$ http://www.inmet.gov.br/sonabra/maps/automaticas.php $>$. Acesso em: 18 jul. 2009.

INSTITUTO BRASILEIRO DE GEOGRAFIA E ESTATÍSTICA (IBGE). Levantamento Sistemático da Produção Agricola. Rio de Janeiro. 2009. Disponível em: $<$ ftp://ftp.ibge.gov.br/Producao_Agricola/Levantamento_ Sistematico_da_Producao_Agricola_\%5Bmensal\%5D/ Fasciculo/2009/>. Acesso em: 29 jun. 2010.

MACHADO, C. F. et al. Divergência genética entre genótipos de feijoeiro a partir de técnicas multivariadas. Ciência Rural, v. 32, n. 02, p. 251-258, 2002.
MELO, W. M. C.; PINHO, R. G. V.; FERREIRA, D. F. Capacidade combinatória e divergência genética em híbridos comerciais de milho. Ciência Agrotécnica, v. 25, n. 04, p. 821-830, 2001.

MORO, J. R. et al. Dissimilaridade genética em sessenta e quatro linhagens de milho avaliadas para resistência ao complexo enfezamento. Revista de Biologia Ciências da Terra, v. 07, p. 153, 2007.

PASSOS, A. R. et al. Divergência genética em feijão-caupi. Bragantia, v. 66, n. 04, p. 579-586. 2007.

RAO, R. C. Advanced statistical methods in biometric research. New York: John Wiley and Sons, 1952. 390 p.

RINALDI, D. A. et al. Correlação entre heterose e divergência genética estimadas por cruzamentos dialélicos e marcadores moleculares RAPD em populações de milho-pipoca. Bragantia, v. 06, n. 02, p. 183-192, 2007.

SCAPIM, C. A.; CARVALHO, C. G. P.; CRUZ, C. D. Uma proposta de classificação dos coeficientes de variação para a cultura do milho. Pesquisa Agropecuária Brasileira, v. 30, n. 05, p. 683-686, 1995.

SILVA, R. M. da. Estudo do sistema reprodutivo e divergência genética em cupuaçuzeiro (Theobroma grandi-florum (willd ex Spreng) Shum.). 1996. 151 f. Dissertação (Mestrado em Genética e Melhoramento de Plantas). Universidade Federal de Lavras, Lavras.

SMITH, S. et al. Association among inbred lines of maize using RFLP and amplification technologies (AFLP and AP-PCR), and correlations with pedigree, F1 yield and heterosis. Maize Genetics Newsletter, v. 68, p. 45, 1999.

VIANA, A. P. et al. Genetic diversity in yellow passion fruit populations. Crop Breeding and Applied Biotechnology, v. 06, p. 87-94, 2006. 